\title{
Effect of Customers' Psychological Power on Service Expectation and Response to Service Failure in a Restaurant Context
}

\author{
Ji-Hern KIM ${ }^{1}$, So Jung AHN ${ }^{2}$
}

Received: August 03, 2020. Revised: August 25, 2020. Accepted: August 30, 2020.

\begin{abstract}
Purpose: The old axion to put the customers first (e.g., customers are king, customers are always right) has been taken for granted in the service sector. In addition, many companies in South Korea are providing customer-first education for employees at their contact points to strengthen their competitiveness. However, excessive increase in the psychological power of the customer can lead to a problem of abuse of power, called 'Gap-jil.' Despite these concerns, most companies hardly discard policies to give high priority to customers because of the assumption that it enhances customer satisfaction leading to organizational performance. However, in recent years, some franchise catering companies have posted warnings about the abuse of power by customers, and a movement to pursue a power-balancing between service providers and their customers is spreading. Research design, data, and methodology: This research is conducted to reconsider the principle of the customer-first perspective and to create a basis for arguments that can solve the problem of abuse of power, which is recognized as a serious social problem. In this research, we test and analyze the effect of customers' psychological power in the context of a restaurant on expectation for service and response to service failure. Result: The result of an experimental study shows that the effect of psychological power on customer satisfaction can be somewhat negative. Also, customers with high psychological power are more likely to have high service expectations. Especially high psychological power of customers causes a difference in the expectation level of human factors such as employee attitude, while the difference in expectations of nonhuman factors such as restaurant atmosphere was not statistically significant. In addition, when customers with high psychological power encounter service failure situation, they are more likely to feel disappointment and regret with a service provider. Meanwhile, the effect of psychological power on complaining behaviors are not significant. Conclusions: The findings of this research provide meaningful implications that the service providers should reconsider their existing corporate culture and management policies that put customers first. In addition, the result of this research is provided meaningful opportunities to review the management philosophy for the company's customers and the education philosophy for the employee education.
\end{abstract}

Keywords : Psychological Power, Service Satisfaction, Service Expectation, Service Failure, Regret, Complaining Behaviors

JEL Classification Code: L10, L2, L8.

\section{1. 서론}

1 First Author's Affiliation: Associate Professor, School of Business, Sejong University, Seoul, South Korea. Email: jihern@sejong.ac.kr

2 Corresponding Author's Affiliation: Doctoral Candidate, School of Business, Sejong University, Seoul, South Korea, Email: florence203175@gmail.com

(๑) Copyright: The Author(s)

This is an Open Access article distributed under the terms of the Creative Commons Attribution Non-Commercial License (https://creativecommons.org/licenses/by-nc/4.0/) which permits unrestricted non-commercial use, distribution, and reproduction in any medium, provided the original work is properly cited.
서비스 분야에서는 오래전부터 "고객은 왕이다"는 고객 최우선 주의 문화가 강조되어왔다. 리츠칼튼 호텔의 창립자인 세자르 리츠 (Cesar Ritz)가 처음 사용한 것으로 알려진 이 말은, 이후 '백화점 왕'이라는 별명을 가진 존 워너 메이커 (John Wanamaker)의 "고객은 항상 옳다"는 말과 함께 서비스 분야의 대표적인 기업철학으로 주목받고 있다. 한국에서도 많은 기업들이 서비스 경쟁력을 강화한다는 명목 하에, 특히 고객접점 직원들에게 고객을 왕처럼 받들어야 한다는 교육을 강조하고 있다. 하지만 최근 한국사회에서 심각한 문제로 인식되는 갑질 문제의 핵심원인은 심리적 파워 (Psychological Power)의 과도한 증가에 따른 
권력남용이라는 점을 감안할 때 (Jun, Kim, \& Rowley, 2019), 고객들로 하여금 지나친 파워를 느끼게 하는 고객 최우선 주의 서비스 문화는 바람직하지 않을 수 있다 (Min \& Kim, 2013). 특히 2015 년 한국의 한 백화점 매장에서는 쥬얼리 무상수리를 거절했다는 이유로 화가 난 고객을 달래기 위해 2 명의 여성직원이 무릎을 끓은 사건이 있었고, 이를 계기로 고객의 갑질 문제에 대한 사회적 경각심이 매우 높아졌다. 마침내 프리미엄 도시락을 판매하는 프랜차이즈 기업인 스노우폭스 코리아 (Snowfox Korea)가 종업원을 함부로 대하는 고객들은 쫓아내겠다는 공정서비스 안내문을 발표하였고, 일부 프랜차이즈 외식기업들이 매장 앞에 고객들의 갑질행동에 대한 경고문을 부착하면서 이른바 워커벨 (Worker and Consumer Balance)을 추구하는 움직임이 확산되고 있다.

심리적 파워에 관한 과거 연구들은 지각된 파워수준이 높은 사람들이 그렇지 않은 사람들에 비해 남의 애기를 잘 경청하지 않고, 자신의 고정관념에 따라 행동하며, 상대방에 대한 공감능력이 현저히 떨어짐을 보여준다 (Min \& Kim, 2013; Piff, Stancato, Côté, Mendoza-Denton, \& Keltner, 2012). 또한 테이블에 발을 올리거나 바닥에 담배를 버리는 것과 같은 비도덕적인 행동을 할 가능성도 높다 (Van Kleef, Homan, Finkenauer, Gundemir, \& Stamkou, 2011). 이는 고객을 왕으로 바라보는 고객 최우선 주의는 고객들의 지각된 파워수준을 높여 갑질 문제를 발생시키는 원인이 될 수 있음을 말해준다. 그럼에도 불구하고 여전히 많은 서비스 기업들이 고객 최우선 주의 관점을 버리지 못하는 이유는 고객의 만족도를 증가시켜 기업성과를 개선시킬 수 있다는 고정관념 때문이다 (He, Li, \& Lai, 2011). 하지만 이를 실증분석한 연구는 찾아보기 어렵다. 만약 고객 최우선 주의가 고객의 만족도에 오히려 해가 되는 것으로 밝혀진다면 고객의 갑질 문제를 야기시킬 수 있는 기존 서비스 관점은 변화가 필요하다고 주장할 수 있다. 따라서 본 연구는 실증분석을 통해 이를 검증하는데 목표가 있다.

기대 불일치이론 (Expectancy Disconfirmation)에 따르면 서비스 분야의 만족도 (Satisfaction)는 기대 (Expectation) 대비 성과 (Performance)로 판단한다 (Au \& Tse, 2019). 이는 기대수준이 높으면 성과가 좋다고 하더라도 만족도가 낮아질 수 있음을 의미한다. 따라서 본 연구는 먼저 고객 최우선 주의로 발생한 고객의 지각된 파워수준의 증가가 서비스에 대한 사전기대에 어떤 영향을 미치는지 알아보고자 한다. 만약 파워수준의 증가가 서비스 기대수준을 증가시킨다면, 서비스 경험의 만족도에 부정적인 영향을 미칠 가능성이 있다. 또한 지각된 파워수준의 증가는 전반적인 서비스 기대수준을 증가시키더라도 서비스의 세부항목들 (예, 직원들의 응대, 신속한 메뉴제공, 레스토랑의 분위기 등)에
대하여 상이한 차이를 발생시킬 수도 있다 (Andaleeb \& Conway, 2006). 따라서 세부항목들 중 어떤 부분에 대한 서비스 기대수준이 상대적으로 증가하는지 파악하는 것은 서비스 만족도 개선을 위한 전략수립에 도움을 줄 수 있다.

한편 고객의 파워수준 증가는 서비스 실패 (Service Failure)에 따른 실망 (Disappointment)과 후회 (Regret), 불평행동 (Complaining Behaviors)에 영향을 미칠 가능성이 있다. 최근 연구결과에 따르면, 지각된 파워수준이 높은 고객은 서비스 실패 발생 시에 실망과 후회가 크고, 불평행동을 할 가능성이 높다 (Min, Joireman, \& Kim, 2019). 하지만 또 다른 연구에서는 파워수준이 높은 고객은 서비스 실패 상황 자체를 대수롭지 않게 생각하기 때문에 부정적인 반응이 줄어 들 수 있다고 주장한다 (Sembada, Tsarenko, \& Tojib, 2016). 따라서 이러한 상반된 주장이 연구 맥락에 따라 어떻게 달라질 수 있는지 검증할 필요가 있다. 뿐만 아니라 불평행동은 그 유형에 따른 차이가 존재할 가능성이 있다. 예를 들면, 파워수준이 높은 고객들은 현장에서 종업원이나 매니저에게 항의하는 직접불평 행동 (Direct Complaints)이 증가하는 반면, 지인 또는 온라인 채널에서 부정적인 구전을 하는 간접불평 행동 (Indirect Complaints)은 줄어들 수 있다. 따라서 본 연구는 불평행동의 유형을 세분화하여 심리적 파워의 효과를 좀 더 구체적으로 살펴보고자 한다.

요컨대 본 연구는 고객 최우선 주의 관점이 고객의 지각된 파워수준을 높여 서비스 기대감을 증가시키고 서비스 실패 시 부정적 반응을 증가시킬 수 있음을 보여주기 위한 목적에서 진행하였다. 이를 통해 서비스 분야에서 오랫동안 관행으로 여겨온 고객 최우선 주의 원칙을 재고하고 심각한 사회적 문제로 인식되고 있는 고객 갑질 문제를 해결할 수 있는 주장의 근거를 만들고자 한다. 이후 논문의 내용은 다음과 같다. 먼저 심리적 파워에 관한 기존 문헌연구를 통해 4 개의 가설을 도출한다. 다음으로 가설검정을 위해 시행한 실험의 절차 및 방법을 설명한 후, 데이터 분석 결과를 제시한다. 마지막으로 분석결과를 바탕으로 본 연구의 이론적, 실무적 시사점과 한계점을 논한다.

\section{2. 이론적 배경 및 연구가설}

\section{1. 심리적 파워와 서비스 기대}

심리적 파워 (Psychological Power)는 사회적 관계에서 가치 있는 자원에 대한 비 대칭적인 통제력에 대한 인식으로 정의될 수 있다 (Magee \& Galinsky, 2008). 쉽게 말하자면, 내가 타인을 원하는 대로 
통제할 수 있다고 인식하는 경우 심리적 파워수준이 높다고 할 수 있다. 먼저 심리적 파워는 오랫동안 유지되는 기질적 특성으로 볼 수도 있다 (Chronic Power). 예를 들어 해병대에 입대하여 오랫동안 강도높은 훈련을 받은 경우, 제대 후에도 평생을 다른 사람들을 자신의 힘으로 통제할 수 있다는 생각을 가지며 살아갈 가능성이 있다. 또한 외동 아이로 가정에서 부모들의 떠받음을 오랫동안 누리며 성장한 경우 성인이 된 후에도 지속적으로 높은 파워수준을 인식할 가능성이 크다.

한편, 심리적 파워는 파워와 관련된 내외적 자극 (Power-related Internal and/or External Stimuli)에 의해 일시적으로 변화하기도 한다 (State power). 따라서 심리적 파워에 관한 과거 연구들은 파워수준을 조작하기 위해 실험 참가자들을 파워와 관련된 단어들에 노출시키거나 (Galinsky, Magee, Gruenfeld, Whitson, \& Liljenquist, 2008), 파워 수준을 변화시킬 수 있는 몸 동작을 수행하도록 요구한다거나 (Cuddy, Schultz, \& Fosse, 2018), 파워수준이 다른 역할극을 수행하도록 하는 (Hashimoto \& Karasawa, 2018) 등 다양한 방법들을 활용하였다.

심리적 파워는 만성적이든, 일시적이든 인간의 인지 (Cognition), 태도 (Attitude), 행동 (Behavior)에 상당한 영향을 미치는 것으로 알려져 있다 (Choi, Park, \& Yoon, 2018). 고파워 수준을 느끼는 사람들은 상대적으로 자기 중심적인 정보처리 (Self-oriented Information Processing)의 가능성이 높고, 자신의 지식 (Knowledge)과 기술 (Skill)에 대한 지나친 자신감을 보이는 경향이 있다 (Sembada et al., 2016). 또한 타인의 의견과 조언을 무시하고 자신이 기존에 가지고 있던 고정관념에 따라 의사결정을 하는 경향이 있다 (Goodwin, Gubin, Fiske, \& Yzerbyt, 2000). 따라서 모 브랜드 (Parent Brand)에 대한 고정관념이 중요한 영향을 미치는 브랜드확장 (Brand Extension)의 효과가 더 크게 나타날 가능성이 있다 (Min \& Kim, 2012). 또한 심리적 파워가 높은 사람들은 광고메시지에 주의 (Attention)를 덜 기울이고, 따라서 메시지에 대한 회상능력 (Recall)이 낮아질 수 있다 (Min \& Kim, 2013). 뿐만 아니라 심리적 파워가 높은 사람들은 타인의 입장에서 생각하는 공감능력이 낮아지고 타인을 낮춰보며 명령과 지시를 하려고 하고 (Galinsky, Magee, Inesi, \& Gruenfeld, 2006), 바닥에 담배를 버리거나 테이블에 발을 올리는 등 비도덕적인 행동을 할 가능성이 높아진다 (Van Kleef et al., 2011). 따라서 잘못된 파워인식이 한국 사회에서 문제가 되고 있는 권력의 남용현상인 갑질을 발생시킬 가능성이 있다 (Jun et al., 2019).

지금까지 논의한 바를 근거로, 고객 최우선 주의 메시지에 노출된 고객들은 심리적 파워수준이 증가될 것이라 기대할 수 있다. 심리적 파워수준은 일시적인 자극에 의해서도 쉽게 조작될 수 있기 때문이다. 또한 고파워를 느끼는 고객들은 서비스를
제공하는 기업의 입장을 무시하고 자기 중심적인 판단에 따라 정보를 처리할 가능성이 있다. 따라서 자신보다 파워수준이 낮은 대상으로부터 과도한 서비스를 요구할 가능성이 높으므로 서비스의 기대 수준이 높아질 가능성이 있다. 이를 근거로 다음과 같은 가설 1 과 가설 2 를 도출하였다.

H1. 고객 최우선 주의 메시지에 노출된 고객은 심리적 파워수준이 증가될 것이다.

H2. 심리적 파워수준이 높은 고객은 서비스 기대수준이 높게 나타날 것이다.

\section{2. 심리적 파워와 서비스 실패에 대한 반응}

심리적 파워는 서비스 실패에 대한 고객의 반응에 영향을 미칠 수 있다. 흥미롭게도 이와 관련된 최근 연구들은 상반된 결과를 제시하고 있으며, 그 이유를 설명하는 논리에 있어서도 차이가 존재한다. 먼저 Min et al. (2019)는 레스토랑의 메뉴판에 "고객은 항상 옳다"는 메시지를 넣어 심리적 파워수준을 조작한 후 서비스 실패가 발생하였을 경우 고객의 반응에 차이가 있는지 분석하였다. 그 결과 심리적 파워수준이 높은 경우 상대적으로 사회적 관계에 대한 민감도 (Sensitivity about Social Relationship)가 낮기 때문에 서비스 실패 시 실망과 후회, 불평행동의 가능성이 더 높아질 수 있음을 보였다. 반대로 심리적 파워수준이 낮은 경우 함께 동행한 사람이나 주변에서 식사를 하고 있는 사람들에게 좋지 않은 인상을 줄 수 있다는 생각에 스스로 화를 가라앉히고 불평행동을 자제하는 것으로 나타났다.

한편 Sembada et al. (2016)은 심리적 파워가 높은 고객들이 오히려 분노를 느끼거나 보상을 요구할 가능성이 높다고 주장한다. 왜냐하면 서비스 실패 그 자체를 덜 심각하게 생각하고 자신이 통제 가능하다고 느끼기 때문이다. 예를 들어, 고파워를 느끼는 사람들은 에어컨 바람의 방향이 자신의 얼굴 정면으로 올 때에도 자리 변경을 요청하거나 에어컨의 방향을 바꿔 달라고 언제든 요청할 수 있다고 생각하기 때문에 불평행동을 상대적으로 적게 할 가능성이 크다. 특히 서비스 실패 후 서비스 제공업자가 잘못을 인정하고 진정성 있는 사과를 하는 등 서비스 회복 (Senvice Recovery)을 위해 충분히 노력할 경우 불평행동은 더욱 감소할 수 있다 (Hashimoto \& Karasawa, 2018). 하지만 서비스 실패가 일회성에 그치지 않고 반복되는 경우에는 오히려 불평행동이 증가할 수도 있다. 또한 에어컨의 방향과 같은 당장 서비스 회복이 가능한 경우와 달리, 주문한 식사가 늦게 나오는 것과 같은 서비스 실패의 경우 Sembada et al. (2016)의 주장보다는 Min et al. (2019)의 
주장이 더 설득력이 있어 보인다. 즉, 심리적 파워수준이 높은 경우에 실망과 후회, 불평행동의 가능성이 증가할 수 있다.

한편 불평행동에도 여러가지 유형이 존재한다는 점에 주목할 필요가 있다. Choi (2016)는 개인이 직접 보상을 요구하는 개인적 불평행동과 소비자단체와 같은 공식 기관을 통해 보상을 요구하는 집단적 불평행동으로 구분한 후 심리적 파워수준이 불평행동에 미치는 효과를 분석하였다. 그 결과 유형에 관계없이 심리적 파워수준이 높으면 불평행동이 증가하는 것으로 확인되었다. 하지만 Min et al. (2019)가 언급한 것과 같이 심리적 파워가 불평행동에 미치는 효과는 사회적 관계 비용이 중요하다는 점을 고려하면 불평행동의 유형을 다른 차원으로 구분하는 것이 필요할 것으로 보인다. 즉, 서비스 실패가 발생한 후 현장에서 종업원이나 매니저에게 직접적인 불평 (Direct Complaints)을 하는 사회적 관계 비용이 높은 불평행동과, 향후 지인에게 부정적인 구전을 하거나 온라인채널을 통해 불편한 경험을 공유하는 사회적 관계 비용이 낮은 간접적인 불평 (Indirect Complaints)으로 나눌 수 있다. 만약 파워수준이 높은 경우에는 (낮은 경우에 비해), 현장에 있는 타인의 시선 등을 크게 신경쓰지 않을 가능성이 높기 때문에 직접불평의 가능성이 증가하고, 이는 서비스 실패에 대한 사과를 받거나 회복의 기회를 높여 간접불평의 가능성이 낮아질 가능성이 있다. 따라서 다음과 같은 가설 3 과 가설 4 가 도출되었다.

H3. 심리적 파워수준이 높은 고객은 서비스 실패 시 실망과 후회가 높게 나타날 것이다.

H4. 심리적 파워수준이 높은 고객은 서비스 실패 시 직접불평의 가능성은 높고, 간접불평의 가능성은 낮게 나타날 것이다.

\section{3. 실험}

\section{1. 실험방법}

전문 리서치 기관에 의뢰하여 만 23 세-39 세 대한민국 남녀 71 명 (남: 35 명, 여: 36 명)의 패널을 대상으로 온라인 조사를 실시하였다. 먼저 설문 문항에 응답하기 전 제시할 시나리오를 개발하였다. 친한 친구와 식사를 위해 레스토랑을 방문하는 상황을 가정한 후, 실험 참가자를 두 집단으로 나누어 첫 번째 집단 (실험집단: 37 명)은 레스토랑 입구에서 "고객 최우선 주의" 서비스 안내문을 보는 상황으로 설정하였고, 두번째 집단 (비교집단: 34 명)은 "추석 연휴 휴일"에 관한 안내문을 보는 상황으로 설정하였다. 서비스 안내문에는 내용을 이해하는데 도움이 될 만한
픽토그램 (Picto-Gram)을 삽입하였으며, 두 집단의 인지적 노력수준 (Cognitive Effort)을 통제하기 위해 55 자 내외의 비슷한 글자 수를 사용하였다 (See Appendix 1).

다음으로 집단간 심리적 파워수준의 차이를 평가하기 위해 Sembada et al. (2016)에서 사용한 3 개 문항이 본 연구에 맞게 수정되어 사용되었다 $(\alpha=.957)$. 본 연구에 사용된 모든 설문 문항 (인구 통계학적 질문 제외)은 응답자가 각 문항에 대한 동의 정도를 7 점 척도로 평가하도록 한 후, 다문항으로 측정된 구성개념 (Construct)의 경우 평균값이 분석에 사용되었다. 각 구성개념별 구체적인 설문문항은 Appendix 2 에 정리되었다.

레스토랑의 서비스에 대한 전반적 기대수준을 측정하기 위한 2 개 문항 $(\gamma=.883)$ 과 레스토랑에 대한 만족도에 영향을 줄 수 있는 세부적인 항목 (직원응대, 위생상태, 분위기, 서비스의 신속성)에 대한 기대수준을 측정하기 위한 4 개 문항은 Andaleeb and Conway (2006)에 사용된 문항들을 본 연구의 내용에 맞게 수정하여 사용되었다.

이후 서비스 실패와 관련된 다음과 같은 시나리오를 두 집단 모두에게 제시하였다. "귀하와 친구는 레스토랑 입구에서 <고객서비스 안내문>을 보고 입장한 후 직원으로부터 자리를 안내받았습니다. 메뉴를 잠시 살펴본 후 귀하는 친구의 동의를 얻어 1 인당 45,900 원의 스테이크를 주문했습니다. 주문 후 40 분이 지나도 물 이외에 어떤 음식도 나오지 않아, 귀하는 직원에게 문의하였고 곧 나온다는 대답을 들었습니다. 하지만 그 후 20 분이 지나서야 음식이 나왔습니다. 주문 후 음식이 나오기까지 총 1 시간이 소요되었습니다." 다음으로 서비스 실패에 따른 실망과 후회 정도의 차이를 평가하기 위해 Bougie, Pieters, and Zeelenberg (2003)에서 서비스 불만족 측정을 위해 사용한 문항들을 참조하여 개발한 3 개의 문항을 활용하여 측정하였다 ( $\alpha=.954)$. 불평행동은 Chang, Khan, and Tsai (2012)에서 사용된 문항들을 이용하여 직접불평과 관련된 2 개 문항 $(\gamma=.570)$ 과 간접불평과 관련된 3 개 문항 $(\alpha=.734)$ 으로 측정하였다. 마지막으로 나이, 성별 등을 묻는 인구통계학적 질문을 한 후 설문이 종료되었다.

\section{2. 분석결과}

본 연구에서는 고객 최우선 주의 메시지에 노출된 집단과 연휴 안내문 메시지에 노출된 집단의 서비스 기대와 서비스 실패에 대한 반응에 차이가 있는지 살펴보기 위해 집단간 평균차이를 검정할 수 있는 ANOVA 분석을 여러 차례 실시하였다. 그 결과, 먼저 고객 최우선 주의 메시지에 노출된 집단 $(\mathrm{M}=3.89)$ 이 연휴 안내 메시지에 노출된 집단 $(M=2.85)$ 에 비해 심리적 파워수준이 
유의하게 높은 것으로 나타났다 $(F(1,69)=9.261, p<.01)$. 따라서 가설 1 은 지지되었다. 다음으로 고객 최우선 주의 메시지에 노출되어 심리적 파워수준이 높은 경우 서비스에 대한 전반적인 기대수준이 유의하게 높은 것으로 나타났다 ( $\mathrm{M}=5.365$ vs. $\mathrm{M}=$ 4.294; $F(1,69)=15.091, p<.01)$ 따라서 가설 2 가 지지되었다. 추가적으로 서비스에 대한 사전기대 중 어떤 항목들에 차이가 있는지 확인해보았다. 그 결과 심리적 파워수준이 높은 경우 직원의 응대태도 ( $M=5.62$ vs. $M=4.15, F(1,69)=30.566, p<.01)$, 서비스의 신속함 $(M=5.41$ vs. $M=4.21 ; F(1,69)=20.823, p<.01)$, 위생상태 $(M=5.22$ vs. $M=4.26 ; F(1,69)=11.665, p<.01)$ 에 대해서는 차이가 존재하는 반면, 레스토랑의 분위기 ( $M=4.95$ vs. $\mathrm{M}=4.32 ; \mathrm{F}(1,69)=3.904, \mathrm{p}=.052)$ 에 있어서는 통계적으로 유의한 차이가 없는 것으로 나타났다. 또한 심리적 파워수준이 높은 경우 서비스 실패 시 실망과 후회를 더 크게 느낄 것이라는 가설 3 도 지지되었다 ( $M=5.964$ vs. $M=5.294 ; F(1,69)=4.558, p<.05)$.

마지막으로 파워수준에 따라 직접 불평 의도와 간접 불평 의도에 차이가 있는지 확인한 결과, 예상과 달리 심리적 파워수준은 직접불평 의도 $(M=5.473$ vs. $M=5.177 ; F(1,69)=$ $1.121, p=.293)$ 와 간접불평 의도 $(M=4.982$ vs. $M=4.873 ; F(1,69)$ $=.134, \mathrm{p}=.716)$ 에 모두 유의한 영향을 미치지 못하는 것으로 나타났다. 또한 방향에 있어서도 심리적 파워가 높은 경우 직접불평 의도가 증가하고 간접불평 의도가 감소할 것이라는 기대와 달리, 불평유형에 상관없이 심리적 파워가 높은 경우 불평의도가 큰 것으로 확인되었다. 따라서 가설 4 는 기각되었다.

Table 1 : Result of testing hypotheses

\begin{tabular}{|c|c|c|c|}
\hline Hypothesis & $\mathbf{F}$ & $\mathbf{P}$ & Result \\
\hline $\mathrm{H} 1$ & 9.261 & $<.01$ & Supported \\
\hline $\mathrm{H} 2$ & 15.091 & $<.01$ & Supported \\
\hline $\mathrm{H} 3$ & 4.558 & $<.05$ & \multirow{2}{*}{ Supported } \\
\hline \multirow{2}{*}{$\mathrm{H} 4$} & 1.121 & .293 & \multirow{2}{*}{ Rejected } \\
\cline { 2 - 4 } & .134 & .716 & \\
\hline
\end{tabular}

\section{4. 결론}

\section{1. 연구결과의 요약 및 시사점}

본 연구는 고객이 느끼는 심리적 파워수준이 서비스에 대한 사전 기대와 서비스 실패 시 반응에 미치는 효과를 분석한 것으로
다양한 이론적, 실무적 시사점을 가진다. 먼저 서비스 분야에서 오랫동안 중요하게 여겨온 "고객은 왕이다 (고객은 항상 옳다)"는 고객 최우선 주의 철학이 반드시 바람직하지 않을 수 있음을 보여준다 (Min \& Kim, 2013). 분석결과에 따르면, 고객 최우선 주의는 고객의 심리적 파워를 증가시키고, 서비스에 대한 사전 기대수준을 높여 오히려 서비스 경험의 만족도를 낮출 수 있는 것으로 나타났다. 따라서 고객 최우선 주의가 서비스 경험의 질을 향상시키고, 고객의 만족도를 높여 기업성과에 기여할 수 있다는 가정이 잘못된 것일 수 있음을 보여준다. 따라서 본 연구는 고객 갑질 문제의 원인이 될 수 있는 서비스 분야에서의 고객 최우선 주의 비즈니스 관행을 재고할 수 있는 근거를 제시하였다는 점에 의의가 있다.

특히 서비스 분야에서 고객접점 직원들은 감정 노동자들로 분류될 만큼 고객들의 파워남용에 따른 스트레스로 고통 받고 있다 (Moon, Hur, \& Jun, 2013). 고객만족도를 향상시킨다는 명목 하에 자신의 진정한 감정을 드러내지 않고 고객이 원하는 과도한 요구들을 그대로 수용하도록 교육을 받는 경우도 적지 않다 (Hur, Han, Yoo, \& Moon, 2015). 본 연구는 이러한 직원 교육은 오히려 고객의 권력남용 가능성만 증가시킬 뿐, 고객 만족도를 제고하는데 도움이 되지 않을 수 있음을 보여준다. 따라서 본 연구결과는 기업의 고객에 대한 경영철학 뿐 아니라 직원에 대한 교육 철학을 다시 한번 점검해볼 수 있는 계기를 제공할 수 있다는 점에 의의가 있다.

추가적으로 본 연구는 기존 연구에서 다루지 않았던 심리적 파워수준의 증가가 어떤 분야에 대한 서비스 기대수준을 증가시키는지를 구체적으로 분석하였다는데 시사점이 있다. 특히 종업원의 서비스태도에 대한 기대감의 차이가 가장 크게 나타난 반면, 레스토랑의 분위기와 같은 외형적 요소에 대한 기대감의 차이는 통계적으로 유의하지 않았다. 이는 심리적 파워가 사회적 관계에서의 힘의 불균형으로 정의된다는 점을 감안할 때, 비인적 요소보다는 인적요소에 대한 서비스 기대감에 특히 큰 영향을 미친 것으로 추론해볼 수 있다.

한편 본 연구는 심리적 파워가 유형에 관계없이 불평행동 의도에는 유의한 영향을 미칠 수 없음을 보여준다. 가설 4 가 기각된 것에서도 알 수 있듯이 이는 예상하지못한 결과이다. 또한 심리적 파워수준이 높은 고객의 불평행동 의도가 높다고 주장한 $\mathrm{Min}$ et al. (2019)의 연구나 심리적 파워수준이 낮은 고객의 불평행동 의도가 오히려 높다고 주장한 Sembada et al. (2016)의 연구와 차이가 있다. 본 연구 결과를 통계적 유의성을 배제하고 방향성만 고려한다면 Min et al. (2109)의 연구결과와 가깝다고 볼 수 있다. 본 연구의 데이터로는 확인이 불가하지만, 기존 
연구결과와의 차이가 어쩌면 서비스 실패상황의 유형이 다르기 때문인지도 모른다. 즉, 서비스 실패상황의 여러 특성들 (예, 심각성, 관여도 등)이 심리적 파워수준이 불평행동에 미치는 효과를 조절하기 때문일 가능성이 있다. 따라서 본 연구는 다양한 조절변수를 고려한 연구들을 향후 진행할 수 있는 논리적 근거를 제시하였다는 점에서 이론적 시사점이 있다.

\section{2. 연구의 한계 및 향후 연구 과제}

\section{본 연구는 여러 의미 있는 시사점을 제공하고 있음에도} 불구하고 다음과 같은 몇 가지 한계점이 있다. 따라서 향후 연구에서는 보완이 필요하다. 첫째, 고객의 심리적 파워 수준을 고파워 수준과 중립 수준의 두 가지로만 구분하였다. 하지만 최근 갑질 문제가 심각해짐에 따라 종업원들에게 무례한 행동을 하면 서비스 이용을 중단하겠다고 선언하는 서비스 제공업체들이 적지 않게 등장하고 있다. 이는 고객의 심리적 파워를 낮추는 효과를 가질 수 있다. 따라서 향후 연구들은 고객의 심리적 파워수준을 고파워, 저파워, 중립 수준으로 3 단계로 나누어 그 효과를 분석할 필요가 있다.

둘째, 본 연구에서는 레스토랑에서 음식이 늦게 나오는 서비스 실패 상황을 시나리오로 제시하였다. 고객 최우선 주의 철학은 레스토랑뿐만 아니라 기내 서비스, 호텔 서비스, 헤어 서비스 등 매우 다양한 서비스 분야에서 오랫동안 강조되어 왔다. 따라서 향후 연구에서는 다양한 서비스 분야에서도 본 연구와 동일한 결과를 얻을 수 있는지 확인하여 주장의 타당성을 강화할 필요가 있다. 뿐만 아니라 앞서 설명한 바와 같이 다양한 서비스 실패 상황의 설정이 매우 중요할 수 있다. 기존 연구들과 달리 심리적 파워가 서비스 실패 시 불평행동에 미치는 효과가 유의하지 않게 나타난 것은 서비스 실패 상황의 특수성 때문일 가능성이 높다. 따라서 향후 연구에서는 서비스 실패 상황의 심각성, 회복 가능성, 일회성이 아닌 반복된 실패의 경우 등으로 실패 상황을 세분화하여 고객들의 반응을 좀 더 정밀하게 분석하고 결과를 비교할 필요가 있다.

마지막으로 본 연구결과는 제한된 샘플과 실험자극을 사용하였다. 고객 서비스의 철학은 국가간 문화간 차이가 있을 수 있으므로 문화비교 연구를 수행하여 결과를 비교하는 것도 의미가 있을 수 있다. 또한 고객 최우선 주의 메시지로 사용된 실험 자극을 본 연구에서는 매장 입구에서 본 상황으로 설정하였는데, 기존 연구와 같이 메뉴판에서 보거나 (Min et al., 2019), 인터넷 광고물 등과 같은 다양한 미디어를 통해 노출되었다고 가정하는 경우에도 동일한 결과가 나타나는지 확인할 필요가 있다.

\section{References}

Andaleeb, S. S. \& Conway, C. (2006). Customer satisfaction in the restaurant industry: An examination of the transaction-specific model. Journal of Services Marketing, 20(1), 3-11

$\mathrm{Au}, \mathrm{A} . \&$ Tse, A. (2019). Expectancy disconfirmation: Effects of deviation from expected delay duration on service evaluation in the airline industry. Asia Pacific Journal of Marketing and Logistics, 31(1), 291-300.

Bougie, R, Pieters, R, \& Zeelenberg, M. (2003). Angry customers don't come back, they get back: The experience and behavioral implications of anger and dissatisfaction in services, Journal of the Academy of Marketing Science, 31(4), 377-393.

Chang, J., Khan, M., \& Tsai, C. (2012). Dining occasions, service failures and customer complaint behaviours: An empirical assessment. International Journal of Tourism Research, 14(6), 601-615.

Choi Soon-Hwa. (2016). Effects of customer relationship quality, customer perceived power, and brand reputation on complaint behaviors. Journal of Distribution Science, 14(9), 111-120.

Choi, W. J., Park, J., \& Yoon, H. (2018). Your gift choice for your boss versus your subordinate would not be the same: The interplay of power and giver-receiver role on consumers' gift preferences. Journal of Business Research, 91, 1-7.

Cuddy, A. J. C., Schultz, S. J., \& Fosse, N. E. (2018). P-Curving a more comprehensive body of research on postural feedback reveals clear evidential value for power-posing effects: Reply to Simmons and Simonsohn (2017). Psychological Science, 29(4), 656-666.

Galinsky, A. D., Magee, J. C., Gruenfeld, D. H., Whitson, J. A., \& Liljenquist, K. A. (2008). Power reduces the press of the situation: Implications for creativity, conformity, and dissonance. Journal of Personality and Social Psychology, 95(6), 1450-1466.

Galinsky, A. D., Magee, J. C., Inesi, M. E., \& Gruenfeld, D. H. (2006). Power and perspectives not taken. Psychological Science, 17(12), 1068-1074.

Goodwin, S.A., Gubin, A., Fiske, S., \& Yzerbyt, V. (2000) Power can bias impression processes: Stereotyping subordinates by default and by design. Group Processes and Intergroup Relations, 3(3), 227-256.

Hashimoto, T., \& Karasawa, K. (2018). Impact of consumer power on consumers' reactions to corporate transgression. PloS One, 13(5), 1-14.

He, Y., Li, W., \& Lai, K. (2011). Service climate, employee commitment and customer satisfaction: Evidence from the hospitality industry in China. International Journal of Contemporary Hospitality Management, 23(5), 592-607.

Hur, W., Han, S., Yoo, J., \& Moon, T. W. (2015). The moderating role of perceived organizational support on the relationship between emotional labor and job-related outcomes. Management Decision, 53(3), 605-624.

Jun, I., Kim, K.I., \& Rowley, C. (2019). Organizational culture and the tolerance of corruption: The case of South Korea, Asia Pacific Business Review, 25(4), 534-553.

Magee, J. C., \& Galinsky, A. D. (2008). Social hierarchy: The self- reinforcing nature of power and status. Academy of Management Annals, 2(1), 351-398. 
Min, D., \& Kim, J. (2013). Is power powerful? power, confidence, and goal pursuit. International Journal of Research in Marketing, 30(3), 265-275.

Min, H., Joireman, J., \& Kim, H. J. (2019). Understanding why anger predicts intention to complain among high but not low power customers: A test of competing models. Journal of Business Research, 95, 93-102.

Min Dongwon, Kim Ji-Hern. (2012). The effect of psychological power on stereotyping of brand extended product. Korean Journal of Advertising, 23(7), 35-60.

Moon, T. W., Hur, W. \& Jun, J. (2013). The role of perceived organizational support on emotional labor in the airline industry. International Journal of Contemporary Hospitality Management, 25(1), 105-123.

Piff, P., Stancato, D., Côté, S., Mendoza-Denton, R., \& Keltner, D. (2012). Higher social class predicts increased unethical behavior. PNAS March 13, 109 (11) 4086-4091

Sembada, A., Tsarenko, Y., \& Tojib, D. (2016). The positive effects of customers' power on their behavioral responses after service failure. Journal of Service Research, 19(3), 337-351.

Van Kleef, G. A., Homan, A. C., Finkenauer, C., Gündemir, S., \& Stamkou, E. (2011). Breaking the rules to rise to power: How norm violators gain power in the eyes of others. Social Psychological and Personality Science, 2(5), 500-507. 


\section{Appendixes}

\section{Appendix 1. Scenario and Power Messages Used in Study}

You decide to serve a meal at a restaurant to a close friend you meet often. When you arrived at the restaurant with your friend, the following $<$ Customer Service Guide $>$ was posted at the entrance. Please read the guide carefully and answer the questions on the next page.

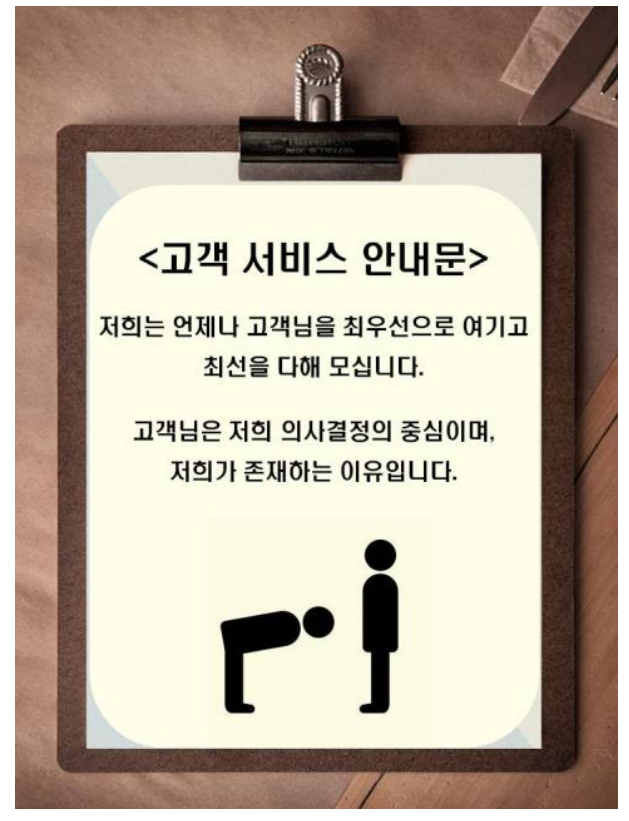

$<$ High Power Message >

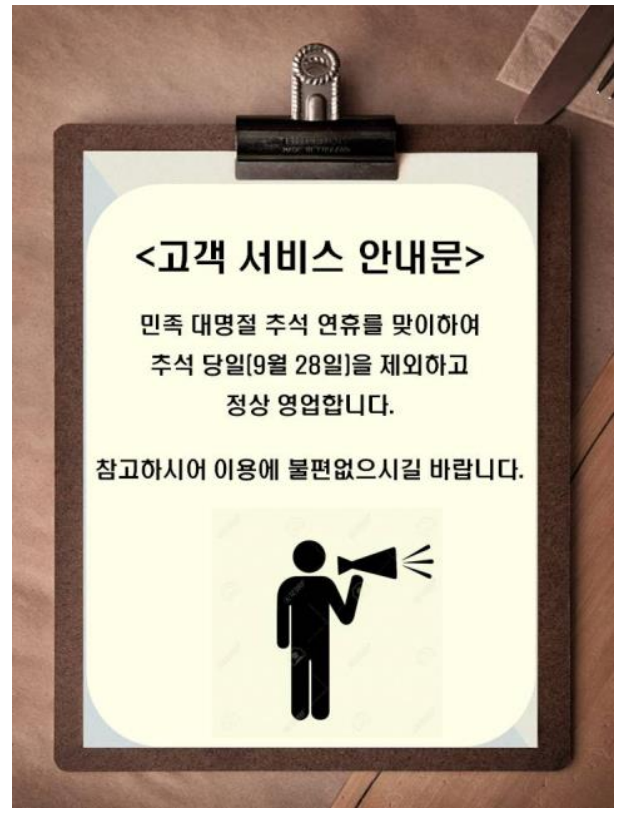

$<$ Neutral Message $>$

Appendix 2. Constructs and Measurement

\begin{tabular}{|c|c|c|}
\hline \multicolumn{2}{|c|}{ Constructs } & Item \\
\hline \multicolumn{2}{|c|}{ Psychological Power } & $\begin{array}{l}\text { 1. I think you can have great power in this restaurant. } \\
\text { 2. I expect I will have the power to control what happens in this restaurant. } \\
\text { 3. I think I will be able to take the initiative in dealing with the problems that arise in this } \\
\text { restaurant. }\end{array}$ \\
\hline \multirow{2}{*}{$\begin{array}{l}\text { Service } \\
\text { Expectatio } \\
\quad n\end{array}$} & Overalls & $\begin{array}{l}\text { 1. The quality of service in this restaurant will be excellent overall. } \\
\text { 2. The dining experience at this restaurant will be generally satisfactory. }\end{array}$ \\
\hline & Contents & $\begin{array}{l}\text { 1. Restaurant staff will pay close attention to customers. } \\
\text { 2. This restaurant's service will come quickly. } \\
\text { 3. The atmosphere of this restaurant will be attractive. } \\
\text { 4. The restaurant's hygiene will be clean. }\end{array}$ \\
\hline \multicolumn{2}{|c|}{ Disappointment \& Regret } & $\begin{array}{l}\text { 1. I regret choosing this restaurant. } \\
\text { 2. Choosing this restaurant was really wrong. } \\
\text { 3. The service at this restaurant was not above my expectations. }\end{array}$ \\
\hline \multirow{2}{*}{$\begin{array}{c}\text { Complaining } \\
\text { Behaviors }\end{array}$} & $\begin{array}{l}\text { Direct } \\
\text { Complaints }\end{array}$ & $\begin{array}{l}\text { 1. I will complain to the employee about this situation. } \\
2 \text {. I will complain to the restaurant's boss or manager about this situation. }\end{array}$ \\
\hline & $\begin{array}{l}\text { Indirect } \\
\text { Complaints }\end{array}$ & $\begin{array}{l}\text { 1. I will tell the people around me about my current bad experiences. } \\
2 \text {. I will advise people around me not to visit this restaurant. } \\
\text { 3. I will write negative comments about this restaurant on the online channel. }\end{array}$ \\
\hline
\end{tabular}

